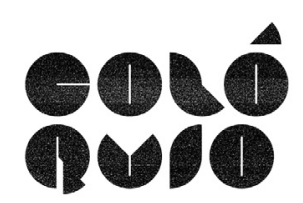

INTERNACIONAL

DE DESIGN
EDIÇÃO 2017

\title{
Inovação e originalidade (e um pouco de sorte...) no projeto gráfico de um livro infanto-juvenil
}

\author{
Airton Cattani; \\ Kátia Cesa;
}

\section{Resumo:}

Este artigo apresenta o desenvolvimento do projeto de um livro infanto-juvenil (CESA, 2016) tendo como tema a sustentabilidade e outras questões ambientais. Inspirado na história clássica de Dom Quixote de la Mancha, foi criado um personagem quase homônimo, Dom Lixote, que defende o reaproveitamento de materiais e outras causas ecológicas, combatendo não mais os moinhos de vento, mas os vilões que assolam o mundo contemporâneo, como o descarte inadequado de lixo, a transformação da água potável em commodity, a utilização excessiva de embalagens e o esgotamento dos recursos naturais. $O$ projeto gráfico do livro também defende estas causas e procura contribuir tanto sob o aspecto literário, divulgando este ideário, quanto sob o aspecto do design e sustentabilidade, utilizando papel reaproveitado e a técnica da dobra francesa para a impressão dos exemplares. O resultado é inovador e original, uma vez que um livro que trata de reaproveitamento tem seu projeto gráfico orientado pela mesma diretriz, o que dá coerência e consistência ao projeto. Além disso, o projeto procura contribuir para o desenvolvimento de uma cultura estético/formal que leve em conta e valorize as peculiaridades de projetos com foco na sustentabilidade.

Palavras-chave: reaproveitamento; sustentabilidade; literatura infanto-juvenil; projeto gráfico. 


\section{Introdução}

$\mathrm{Na}$ sociedade atual, as questões da sustentabilidade deixaram de ser causas defendidas apenas por alguns idealistas para serem incorporadas ao cotidiano de segmentos sociais preocupados com o futuro do planeta. Nesse sentido, a educação formal tem destacado papel no desenvolvimento de uma consciência ambiental em crianças e jovens. É por meio de ações orientadas a este público que os resultados tendem a ser mais efetivos, tendo em vista o caráter mais receptivo destas faixas etárias. Assim, a qualidade de produtos e ações educativas têm uma relação direta com os resultados esperados em termos de incorporação de boas práticas cotidianas com vistas ao cuidado ambiental. Neste cenário, os designers, em suas várias especialidades, têm grande responsabilidade, uma vez que poderão ser agentes de uma cultura comprometida com esta questão.

Este artigo apresenta o processo de projeto de um livro destinado ao público infanto-juvenil, que aborda questões ambientais como a destinação inadequada de lixo, o uso indiscriminado de embalagens e seu descarte inapropriado, a privatização dos mananciais de água potável e sua transformação em mercadoria, e outras situações de esgotamento de recursos naturais. Mas o foco principal do livro é a importância do reaproveitamento, que é empregado não apenas como temática literária, mas é incorporado ao próprio projeto gráfico. Utilizando papel reaproveitado e a técnica da dobra francesa para a impressão dos exemplares, o livro conta a história de Dom Lixote, um herói reciclado, que acredita que é possível colocar em prática o reaproveitamento como uma alternativa viável, tanto ecológica quanto literária e gráfica. Os resultados obtidos evidenciam que projetos deste tipo devem ser pensados desde sua concepção em uma prática integrada e de forma organizada, envolvendo todos os participantes do projeto, podendo conduzir ao desenvolvimento de produtos inovadores e originais. Por outro lado, também contribui para o desenvolvimento de uma cultura que entenda produtos eco-orientados como portadores de uma estética própria, onde questões como aspecto visual e acabamento tenham características que eventualmente os diferenciem de produtos tradicionais, e essas peculiaridades sejam vistas como inerentes à abordagem produtiva focada na sustentabilidade.

\section{Antecedentes}

Os antecedentes deste projeto podem ser localizados em uma oficina de criação de bonecos com sucatas, realizada pela autora do texto na Companhia de Teatro Caixa do Elefante, em Porto Alegre/RS, no ano de 2014. O objetivo da oficina era a criação de bonecos e marionetes a partir de sucatas colocadas à disposição dos participantes. Assim, quando uma garrafa plástica de suco se uniu a tampas de refrigerantes, um estojo de lentes de contato, um medidor de sabão em pó e uma casca de amendoim, surgiu um personagem muito particular; embora ainda mal definido, seu aspecto lembrava um cavaleiro que remetia a Dom Quixote de la Mancha, o famoso cavaleiro andante criado pelo espanhol Miguel de Cervantes no século XVII. Por ser feito de sucatas que poderiam ter como destino o lixo, a associação foi imediata: porque não ser chamado de Dom Lixote? Nesta situação pode ser observada, pela primeira vez no contexto deste projeto, a importância do olhar atento e das referências histórico-culturais no fazer design. Como afirmou Chaves (2016), a qualidade cultural em geral - e a qualidade da cultura gráfica/técnica em particular - do repertório de expressão de um designer são condições necessárias (embora não as únicas) para a formação de uma bagagem cultural que dê suporte teórico-prático para trabalhos igualmente de qualidade. São os conhecimentos de design associados aos de literatura, música, artes, esportes, arquitetura, fotografia, filosofia, cinema, ciências etc. que formarão o repertório com o qual o profissional irá se "alimentar" para criar. Quanto mais rico e amplo este conhecimento, melhores serão as chances de se chegar a um trabalho de qualidade. Neste caso, a referência literária foi fundamental para associar uma criação textual à uma ação em design (que a rigor não tem relação com literatura), produzindo um resultado original e contextualizado.

Esta motivação conduziu à finalização da marionete com foco no personagem cervantino. Assim, foi-lhe adicionado um cavalo também feito de sucatas, cujo nome deveria fazer referência ao herói original: se Dom Quixote tinha seu cavalo Rocinante, era óbvio que Dom Lixote deveria ter seu cavalo Reciclante, remetendo ao original e ao mesmo tempo à causa ecológica que a dupla passaria a defender. Deste modo, Dom Lixote e seu cavalo Reciclante foram sendo finalizados com a utilização 
dos mais variados materiais reaproveitados, tendo em vista o caráter dos personagens já ter sido definido: lacres de latinhas de alumínio para o colete/armadura, prato de plástico para o escudo, restos de tapetes para o corpo do cavalo, rolinhos de papel higiênico e cápsulas de café expresso para as patas, tampas de garrafas PET para os olhos, um velho espanador como lança e assim por diante. O conjunto cavalo/cavaleiro se mantém de pé graças às estruturas interiores que permitem a articulação das partes componentes por um manipulador.

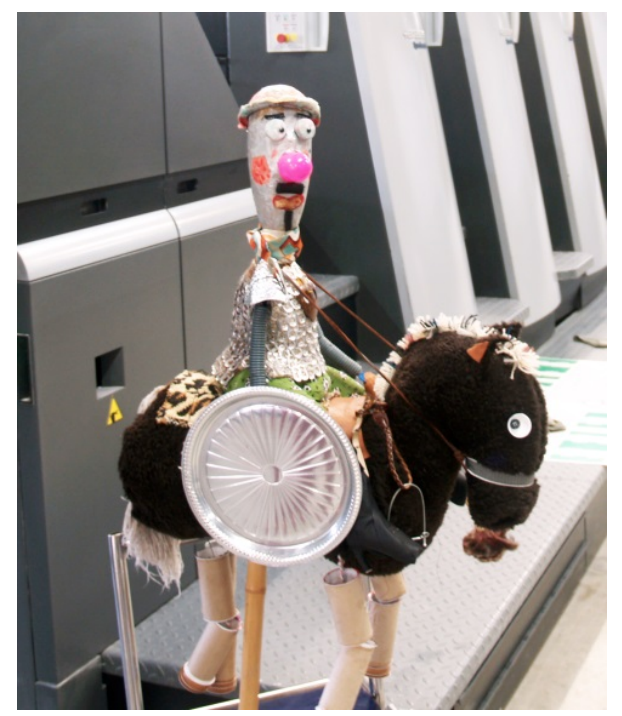

Figura 1 - A marionete Dom Lixote e seu cavalo Reciclante.

Fonte: acervo dos autores.

Uma vez finalizado o conjunto, e a exemplo do original, o personagem precisava de uma boa causa para defender, não se limitando a ser apenas um exercício lúdico. Deste modo foi desenvolvido um texto que relata a origem do personagem e as causas que defende: nascido a partir de sucatas e disposto a enfrentar os terríveis Dragões-que-cospem-lixo que invadem os arroios urbanos, e os gigantes Multi++, que aprisionaram a Princesa Cristalina, a água mais pura do planeta, para vendê-la em garrafinhas plásticas. E, como seu quase homônimo, Dom Lixote só pode iniciar seu bom combate depois de ser sagrado cavaleiro. Assim, a narrativa tem por característica o que Linden (2011, p. 26) chama de "levar ensinamentos aos leitores", ou seja, contribuir para sua formação como cidadão, especificamente para uma formação que destaque a preocupação com a sustentabilidade e outras questões ambientais.

Tendo em vista o caráter paradidático do livro, o texto apresenta alguns trechos traduzidos do original cervantino destacados em itálico. Com isso, além da causa do reaproveitamento de materiais, o texto presta-se para abordagens educacionais também em literatura, mostrando o caráter polivalente da obra.

\section{O projeto gráfico}

Segundo Linden (2013, p. 7), um livro ilustrado que tenha a capacidade de seduzir seus leitores, deve se caracterizar pelas imagens notáveis, pela narrativa cativante, pelo humor e pela originalidade da produção. Este último aspecto teve muita relevância no desenvolvimento do projeto gráfico deste livro, uma vez que o tema do reaproveitamento se revelou instigante e motivador na procura de abordagens editoriais originais que ultrapassassem a óbvia alternativa de utilizar papel reciclado para a impressão dos exemplares.

Assim, o projeto gráfico foi desenvolvido seguindo o que Lupton $(2013$, p. 4) chamou de "mistura de ações intuitivas e intencionais" e Haslam (2007, p. 23) de "mistura de decisões racionais e conscientes que podem ser analisadas e decisões subconscientes que [...] derivam da experiência e criatividade do designer": alguns aspectos estavam claramente definidos e serviram para conduzir o projeto de maneira racional e objetiva; outros, no entanto, foram sendo conduzidos pela intuição, observação e percepção (e também alguma sorte), fazendo com que as soluções surgissem pela 
observação do contexto e da experiência profissional, sem qualquer ideia pré-estabelecida e em um ritmo pessoal em direção ao refinamento do projeto. Esta sistemática também reflete o que Lupton (2013, p. 4) chamou de "diversidade da prática contemporânea de design", intercalando momentos de introspecção e trabalho solitário com momentos de trabalho em equipe. Foi este vai-e-vem entre propostas e soluções, além da alternância entre trabalho individual e coletivo que possibilitou a chegada a uma solução final original, e que pode ser classificado na delimitação de Linden (2011, p. 24) como um livro ilustrado, cuja narrativa se faz de maneira articulada entre texto e imagem, alternando a preponderância texto/imagem; conforme a narrativa, haverá predomínio de um sobre o outro, procurando criar um ritmo de atenção variável.

Como a temática do livro era o reaproveitamento, por uma questão de coerência o projeto gráfico também deveria incorporar esta questão, buscando o equilíbrio entre a solução técnica e cultural, evitando alternativas que priorizassem apenas uma linha ou outra (MANZINI; VEZZOLI, 2002). Por ser considerada óbvia e elementar demais para este projeto, não foi levada em consideração a possibilidade de utilizar papel reciclado para a impressão dos exemplares; embora fosse uma possibilidade coerente para este contexto, buscou-se uma solução mais original. Desta forma, a primeira alternativa levantada para a impressão dos exemplares foi utilizar papel A4 reaproveitado, empregando a técnica da dobra francesa, que consiste em imprimir o papel apenas em uma face, dobrá-lo ao meio (ou em quatro), encaderná-lo e não refilá-lo nas bordas (Figura 2).

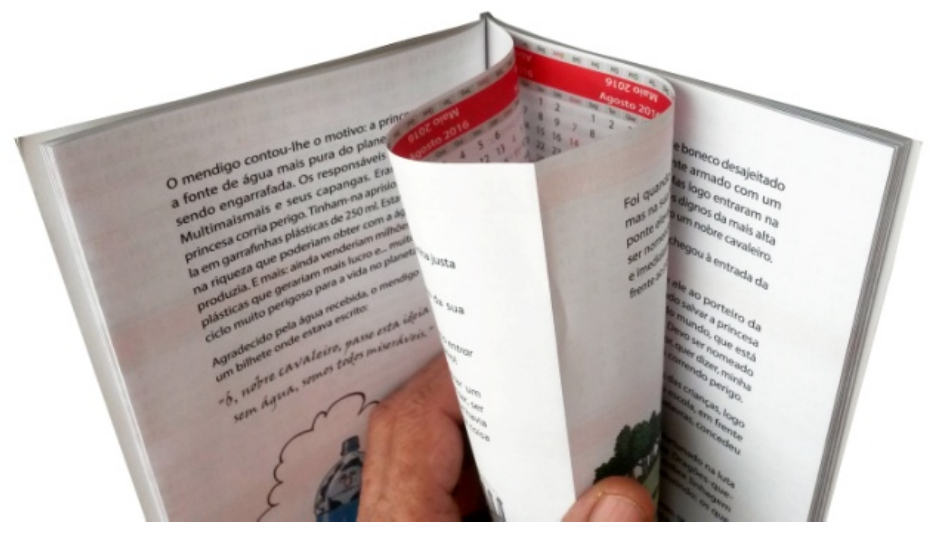

Figura 2 - Dobra francesa com papel dobrado ao meio, sem refilamento da borda. Fonte: acervo dos autores.

Este papel é encontrado com certa facilidade em escritórios e copiadoras, e poderia ser cedido praticamente sem custo. No entanto, a procura e seleção do papel (que deveria ter sido impresso em apenas uma face) revelaram-se pouco viáveis, pois foi levantada a questão de que estes papéis eventualmente teriam em seu verso informações de caráter privado que não deveriam constar em um livro a ser comercializado. Também foi levantada a possibilidade de reaproveitar folhas usadas durante o processo de calibração da impressão (chamadas maculatura ou mala, na gíria dos impressores, embora este nome designe também um tipo de papel reciclado), mas esta alternativa se mostrou inviável, uma vez que esses papéis apresentariam diversas gramaturas e dimensões, além de nem sempre estarem em bom estado, já que algumas vezes o verso também está impresso ou mesmo sujo.

Descartadas estas alternativas, foi feito contato com uma gráfica para verificar outras possibilidades que poderiam viabilizar a edição com foco no reaproveitamento, mas sem passar pela alternativa óbvia de utilizar apenas papel reciclado. Por um acaso muito favorável, em uma visita à gráfica foi observada a existência de uma pilha de papel impresso que seria enviado para a reciclagem: um calendário havia sido impresso com um erro, e seu verso não havia sido impresso e estava em bom estado. As folhas eram de papel offset $70 \mathrm{~g} / \mathrm{m}^{2}$ e mediam 54 x $62 \mathrm{~cm}$. Assim, milhares de folhas estavam à disposição, pois não se vislumbrava qualquer outro destino a elas que não fosse o envio para a reciclagem (Figura 3). Com isso foi possível proporcionar um resultado equilibrado, mesclando soluções técnicas e culturais tradicionais com alternativas relativamente inovadoras focadas na sustentabilidade, como defendido por Manzini e Vezzoli (2002). 


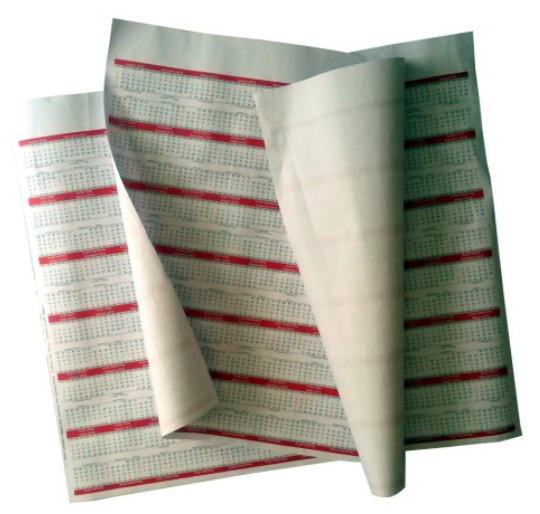

Figura 3 - Papel impresso com erro, como verso intacto.

Fonte: Acervo dos autores

Novamente aqui podemos invocar as afirmações de Chaves (2016), não em relação à uma cultura geral, mas especificamente em relação à cultura técnica: é fundamental ao designer o conhecimento das possibilidades e restrições impostas pela técnica, de modo a valer-se dela na busca das soluções mais apropriadas. A vivência do cotidiano de uma gráfica - o chamado chão de fábrica -, o olhar atento sobre as possibilidades e ao inusitado, a atenção aos princípios norteadores do projeto, aliados ao conhecimento teórico e técnico e a observação de fatos casuais - e um pouco de sorte, é verdade... -, constituíram as condições propícias para o desenvolvimento de um projeto com pleno foco no reaproveitamento. Este processo também reflete a "desvinculação de conceitos previsíveis e lineares existentes na atividade de design", apontados por Moraes (2009, p. 9) como sendo característicos do modelo de fazer design de acordo com a lógica moderna. Segundo o autor, este contexto provocou alterações que alargaram a maneira de pensar e de fazer design, permitindo a adoção de processos de projeto onde a lógica é de outra ordem (ou "desordem", como a adotada neste projeto), de contornos mutantes e imprevisíveis.

A partir destas condições foram detalhadas algumas características do projeto gráfico. Ficou estabelecido que seria mantido o uso da dobra francesa, permitindo a impressão de 8 páginas por folha, o que definiu as dimensões finais da página fechada em $15 \times 25 \mathrm{~cm}$, bem como definiu que o número de páginas deveria ser múltiplo de 8 . Dada a extensão do texto, foi definido em 24 o número total de páginas, sendo utilizadas 3 folhas para a impressão de cada exemplar (Figura 4).

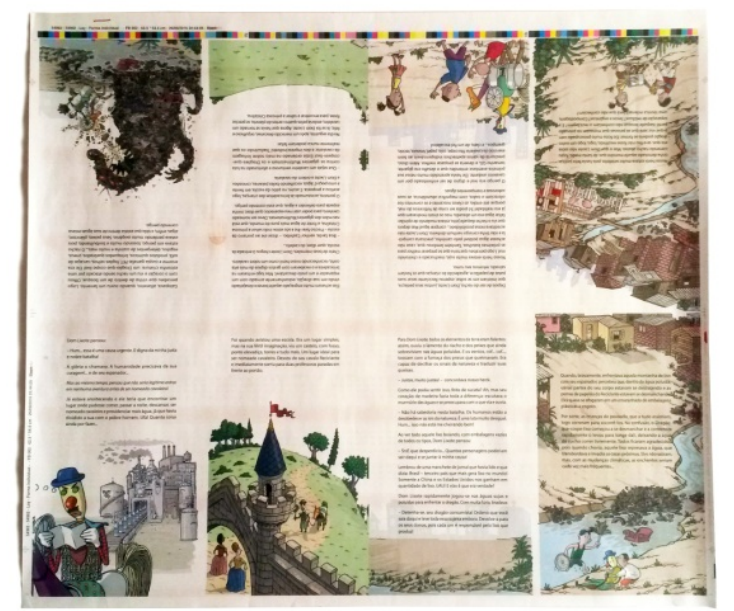

Figura 4 - Imposição das páginas sobre a folha, permitindo a impressão de 8 páginas. Fonte: acervo dos autores.

O passo seguinte foi definir o caráter visual da obra, que deveria estar adequado à faixa etária compreendida entre 8 e 12 anos. Assim, as ilustrações deveriam ter um caráter figurativo intermediário entre o infantil e o adolescente, com contornos bem definidos. Para desenvolver essas ilustrações foi convidado o ilustrador Moa (Moacir Knorr Guterres). Jornalista e editor de arte, Moa tem em seu 
currículo vários prêmios nacionais e internacionais de ilustração, tendo um traço muito definido e característico, considerado adequado para ilustrar a história. $\mathrm{O}$ estilo gráfico das ilustrações adota o contorno delimitado em preto e áreas preenchidas com cores. Todas as ilustrações foram feitas a partir de esboços iniciais, onde era verificada a adequação à mancha do texto (Figuras 5 e 6).
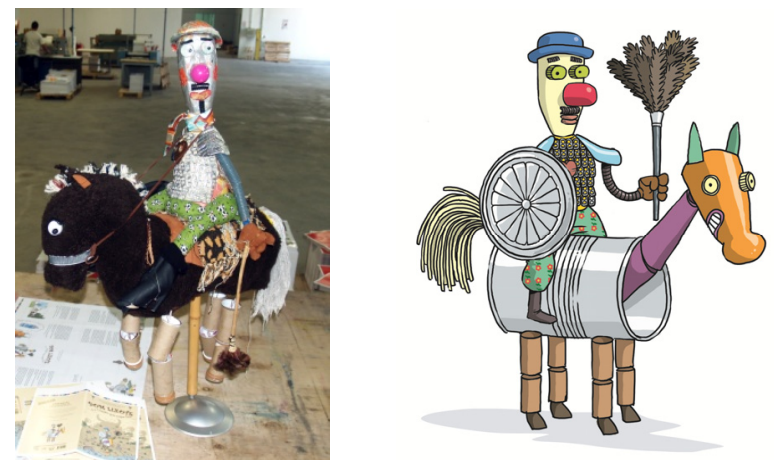

Figura 5 - A marionete (esq.) e o personagem Dom Lixote (dir.), criado pelo ilustrador Moa. Fonte: acervo dos autores.
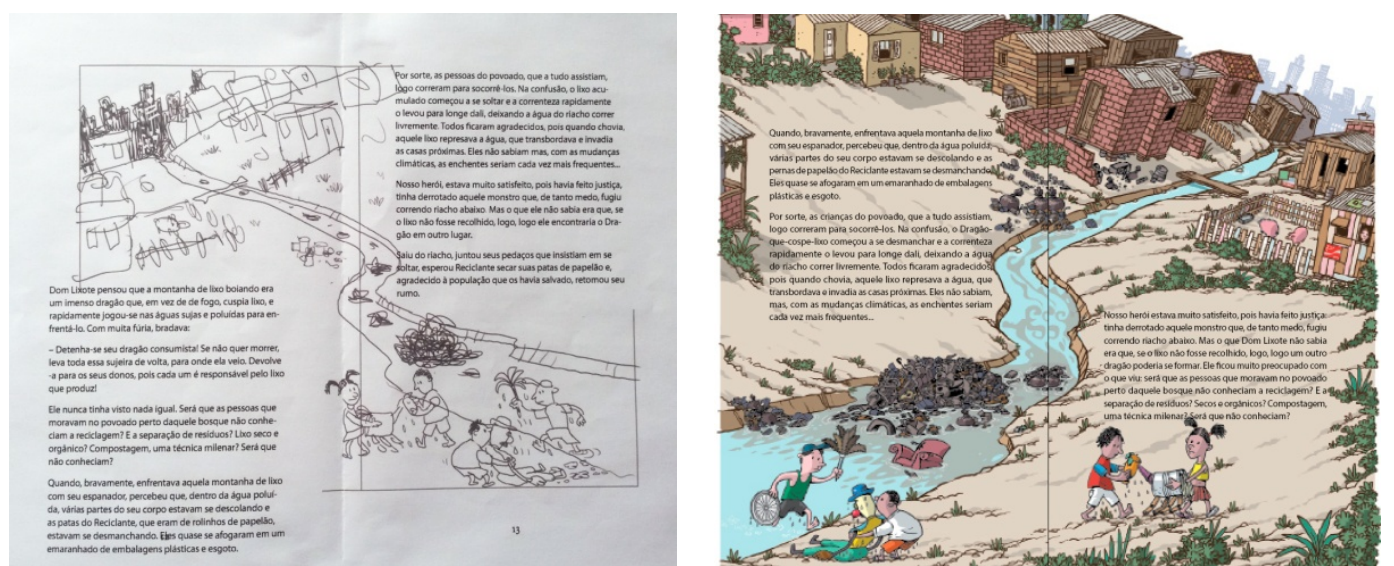

Figura 6 - Esboço inicial (esq.) e solução final (dir.), onde a ilustração foi espelhada e os personagens mudaram de lugar para se adequar à mancha gráfica e evitar a calha central.

Fonte: Acervo dos autores.

O projeto foi sendo aprimorado pelo trio autora/ilustrador/designer em constantes reuniões, onde todos faziam sugestões para o trabalho dos demais, aproximando "atividades de contornos e de fronteiras anteriormente tidas como longínquas" (MORAES, 2009, p. 10). Assim, aspectos do texto, estilo e formato das ilustrações e detalhes gráficos foram sendo definidos à medida que o projeto avançava, em um processo de colaboração e intervenção no trabalho do outro de forma mútua. Esta interação entre os envolvidos alternava situações onde alguns aspectos estavam rigidamente estabelecidos e eram imutáveis, com momentos onde a subjetividade e a imprevisibilidade conduziam os trabalhos. A rigor, esta alternância não costuma ser preconizada nas referências que abordam sobre metodologia projetual, mas neste caso pode-se afirmar que favoreceu o encontro de soluções criativas e originais, adequadas ao escopo do projeto.

Até chegar à solução final, diversos protótipos físicos foram elaborados, onde foram testados e definidos a extensão da obra, as dimensões do livro, a estrutura da narrativa, o caráter das ilustrações, as manchas de texto, as alternativas tipográficas, a diagramação em função do uso da dobra francesa e outros detalhes. Estes protótipos revelaram-se essenciais para entender a materialidade do livro e a escolha entre alternativas viáveis. Boa parte dos protótipos foi impressa em impressora doméstica, em PB e muitas vezes em papeis reaproveitados, sem preocupação com acabamentos (Figura 7). Aprimorar o projeto tendo como base alternativas e protótipos físicos revelou-se extremamente adequado, pois a materialidade permitiu tomar decisões que provavelmente não teriam ocorrido em uma manipulação digital, uma vez que a percepção da realidade física e da realidade digital se dão de forma distinta. Afinal, o que se vê na tela de um computador é percebido de outra maneira quando impresso. 


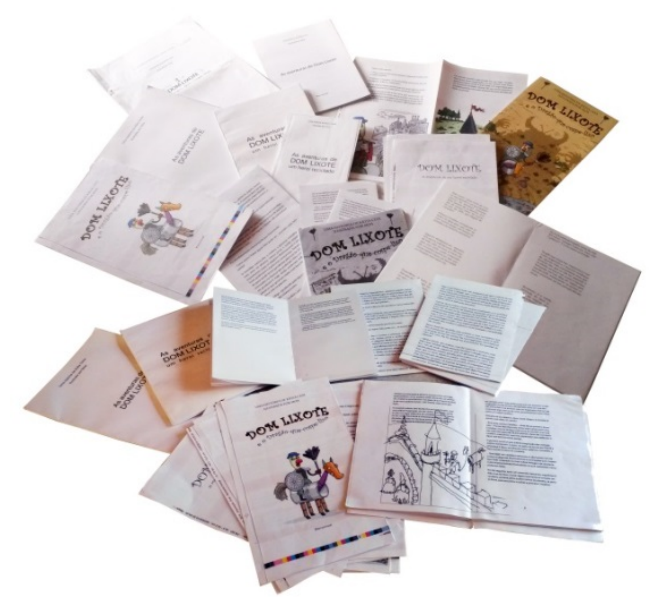

Figura 7 - Protótipos elaborados durante o desenvolvimento do projeto.

Fonte: Acervo dos autores.

A utilização de um papel já impresso em uma das faces levantou algumas dúvidas, entre as quais a sombra provocada pelo verso previamente impresso; como a impressão só continha poucas áreas chapadas e tipografia muito espaçada, este fato não se relevou um problema, pois produziu uma sombra pouco significativa (Figura 8). Este detalhe foi explicado aos leitores em texto ao final do livro. É importante lembrar que em outro contexto e temática (por exemplo, um livro de reproduções fotográficas onde a alta qualidade da impressão gráfica fosse uma exigência), este recurso não poderia ser utilizado. Além disso, também é importante levar em conta a flexibilidade dos envolvidos no projeto: é claro que uma impressão em papel virgem e de boa qualidade traria mais fidelidade de cor e acabamento primoroso ao livro. No entanto, tendo em vista o caráter do projeto, focado no reaproveitamento, aspectos que poderiam ser considerados negativos em outro contexto terminaram por produzir um diferencial positivo.

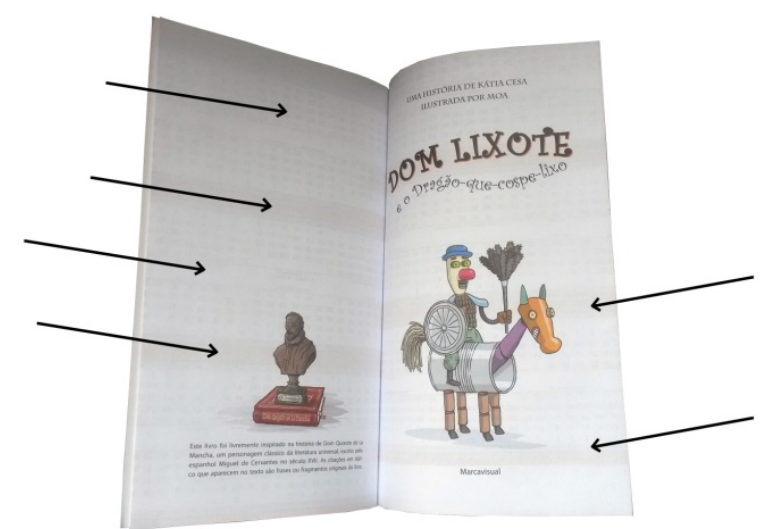

Figura 8 - Ocorrência de áreas de sombra (indicadas pelas setas) ocasionada pela impressão no verso, sem interferência significativa na leitura do texto ou observação das imagens.

Fonte: acervo dos autores.

O tipo de papel e o uso da dobra francesa condicionaram a encadernação, que teve que ser colada, o que por sua vez condicionou as ilustrações, pois este tipo de encadernação faz com que a calha junto às margens centrais não proporcione uma abertura total do livro, o que fez com que a ilustrações evitassem detalhes importantes nesta área. Mas como quase todas as ilustrações são de página dupla, as imagens são duplicadas em $3 \mathrm{~mm}$ para cada lado junto à calha, de modo a não se perder detalhes que seriam ocultados pelo tipo de encadernação (Figura 9). 


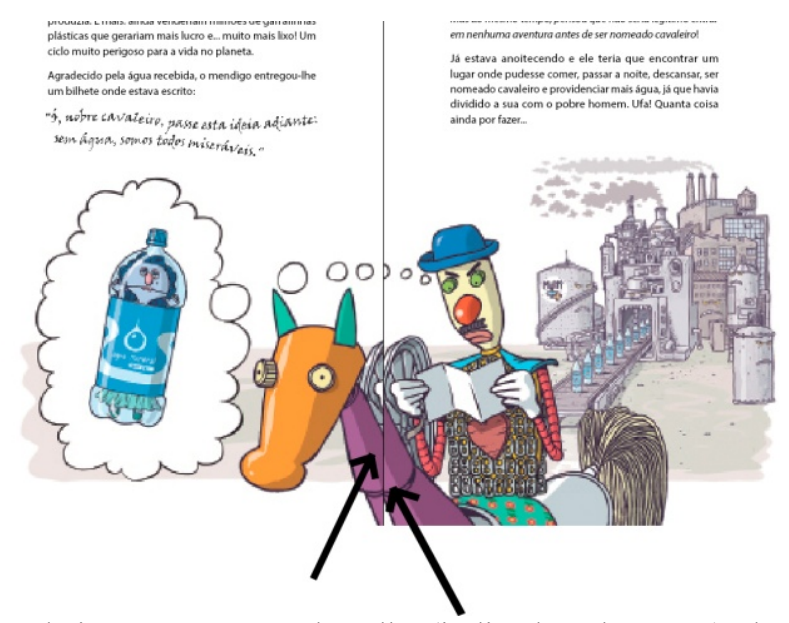

Figura 9 - Duplicação de parte da imagem na área da calha (indicada pelas setas), de modo a não perder detalhes devido ao tipo de encadernação.

Fonte: acervo dos autores.

O material de divulgação impresso também foi produzido com reaproveitamento de papel. Marcadores de páginas foram confeccionados reaproveitando o verso de folhas utilizadas para calibrar as cores em impressões convencionais (maculatura ou mala). Essas folhas normalmente são descartadas, pois as cores impressas durante o processo de calibragem não correspondem ao aspecto final desejado. Assim, o material promocional alinha-se ao ideário de reaproveitamento que orientou todo o projeto (Figura 10).

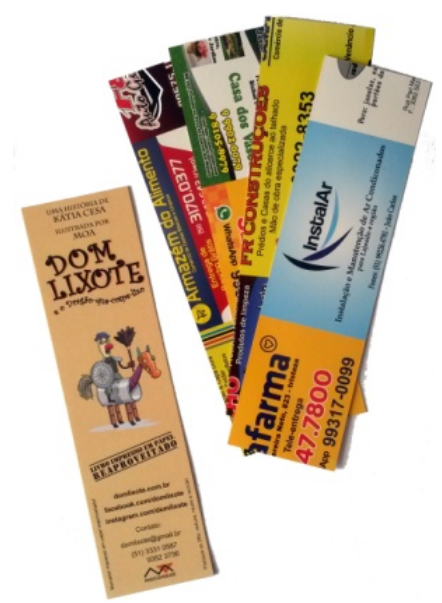

Figura 10 - Marcador de páginas para divulgação do livro, impresso em papel reaproveitado.

Fonte: acervo dos autores

A receptividade do projeto foi muito positiva, tanto por parte de crianças e adolescentes, quanto por parte de adultos. Por ocasião dos lançamentos e sessões de autógrafos foi possível observar a reação dos futuros leitores: enquanto as crianças tinham sua atenção voltada para as ilustrações, os adultos mencionavam a originalidade da dobra francesa e a possibilidade de reaproveitamento do papel como diferenciais. O uso de papel reaproveitado, o surgimento de uma mancha ocasionada pela pré-impressão das folhas, o tipo de encadernação, não foram vistos como "defeitos" do produto, mas inerentes à abordagem adotada no projeto e como um diferencial positivo. Assim, percebe-se uma aceitação, por parte de consumidores sensíveis às questões ambientais, de características inusitadas para um produto com estas peculiaridades, demonstrando viabilidade para aplicações em outros projetos. Antes que esconder características originadas de uma opção produtiva focada na sustentabilidade, optou-se por declará-las, deixando claro que um produto orientado por este viés poderá ter atributos que não são os mesmos que os obtidos em um processo produtivo tradicional. Tais atributos, anteriormente considerados secundários, acabam por tornarem-se diferenciais, alçados à condição de atributos primários (MORAES, 2009, p. 10), valorizando o produto final. 


\section{Considerações finais}

Os resultados obtidos na realização deste projeto permitem afirmar que ações que tenham um comprometimento ambiental podem ser levadas a efeito em diversos campos, desde a editoração até a própria literatura. Para tanto, é necessário adotar um olhar cuidadoso sobre o contexto em que se desenvolverá a ação, de modo a buscar resultados de qualidade em sintonia com princípios de sustentabilidade efetiva, uma vez que a simples adoção de uma atitude ambientalmente correta não garante bons resultados à priori: existem diversos exemplos de produtos confeccionados utilizando materiais reaproveitados ou reciclados que são de qualidade duvidosa sob o ponto de vista estético/formal e mesmo funcional. Outros produtos, por sua vez, apenas empregam o que Diez (2013, p. 124) chamou de "uma retórica da sustentabilidade", incluindo-a apenas em estratégias de "comunicação verde", sem efetivamente modificar seus processos de produção, muitas vezes em descompasso com um cuidado ambiental pleno.

A atenção ao acaso também é uma atitude que pode proporcionar diferenciais positivos ao projeto. Raramente mencionado em obras que tratam de metodologia de projeto - talvez por não ser considerado um aspecto "relevante" ou "científico" -, no contexto deste projeto o acaso revelou-se desencadeador de soluções originais e relativamente inovadoras. Isto mostra que, mesmo não sendo uma atitude calcada em fundamentos científicos, situações casuais e fortuitas associadas aos conhecimentos teóricos e práticos dos projetistas, devem ser observadas atentamente para procurar extrair delas diretrizes para soluções inovadoras.

Por outro lado, também foi comprovado que projetos que envolvam diversos autores e que empreguem processos produtivos não convencionais devem ser pautados por um diálogo constante: a busca pelas melhores soluções pede flexibilidade de todos, desde a metodologia até o acabamento, atendendo as peculiaridades de cada área. Neste projeto os participantes flexibilizaram suas exigências em prol de um resultado final de qualidade sob vários aspectos. Um exemplo disso está em detalhes, como o efeito de sombra, ocasionado pela impressão prévia no verso das folhas, realçada pela baixa gramatura do papel: em outras circunstâncias, seria recomendado um papel de maior gramatura para evitar este efeito, mas o contexto em que estava sendo realizado o projeto fez com que o projeto gráfico incorporasse este efeito como uma consequência necessária da adoção do reaproveitamento. Como se repetiu diversas vezes entre os participantes durante o desenvolvimento do projeto, como uma espécie de mantra, tudo pela causa da sustentabilidade!

Finalmente, é importante salientar que o desenvolvimento de projetos com estas características, além de buscarem aspectos inovadores e originais, também procuram contribuir para o desenvolvimento de uma nova cultura estético/formal, onde a sustentabilidade define novos padrões: um projeto sustentável não necessariamente precisa reproduzir padrões estético/formais de projetos convencionais, ou seja, novas diretrizes de projeto (neste caso focado na sustentabilidade) podem produzir novos padrões estético/formais. A adoção de princípios de sustentabilidade pede também a flexibilidade por parte dos usuários, pois os produtos produzidos nessas condições poderão ter características peculiares, nem sempre semelhantes àquelas dos sistemas de produção convencionais. Será o desenvolvimento crescente de projetos orientados por estas novas diretrizes produtivas que contribuirá para a consolidação de uma cultura orientada para a sustentabilidade e o respeito à questões ambientais. 
Innovation and Originality (and a Bit of Chance ...) in the Graphic Design of a Children's Book

Abstract: This article presents the development of the project of a children's book (CESA, 2016) with the theme of sustainability and other environmental issues. Inspired by the classic history of Don Quixote de la Mancha, a nearly homonymous character, Dom Lixote, was created, who advocates the reuse of materials and other ecological causes, fighting not more windmills, but the villains that plague the contemporary world, as the inappropriate disposal of garbage, the transformation of drinking water into a commodity, the excessive use of packaging and the depletion of natural resources. The graphic design of the book also defends these causes and seeks to contribute both under the literary aspect, disseminating this idea, and under the aspect of design and sustainability, using paper reused for the printing of the copies. The result is innovative and original, since a book that deals with reuse has its graphic design guided by the same guideline, which gives originality and consistency to the project. In addition, the project seeks to contribute to the development of an aesthetic /formal culture that takes into account and values the peculiarities of projects with a focus on sustainability.

Keywords: Reuse; Sustainability; Children's literature; Graphic project

\section{Referências}

CESA, Kátia. Dom Lixote e o Dragão-que-cospe-lixo. Ilustrações de Moa. Porto Alegre: Marcavisual, 2016.

CHAVES, Norberto. Acerca de la calidad gráfica. Disponível em foroalfa.org/articulos/acerca-de-lacalidad-grafica. Acesso em 06/12/2016.

DIEZ, Fernando. Agenda pendiente: medio ambiente y sociedad: los primeros 10 años del siglo XXI. Buenos Aires: Universidad de Palermo, 2013.

HASLAM, Andrew. O livro e o designer II. São Paulo: Edições Rosari, 2007.

LINDEN, Sophie van der. Para ler o livro ilustrado. São Paulo: Cosaf Naify, 2011.

LUPTON, Ellen (Org.). Intuição, ação, criação. Graphic design thinking. São Paulo: Gustavo Gili, 2013.

MANZINI, EZio; VEZZOLI, Carlo. O desenvolvimento sustentável de produtos. São Paulo: Edusp, 2002.

MORAES, Dijon de. O papel atual do design. In: KRUCKEN, Lia (Org.). Design e território.

Valorização de identidades e produtos locais. São Paulo: Studio Nobel, 2009. 